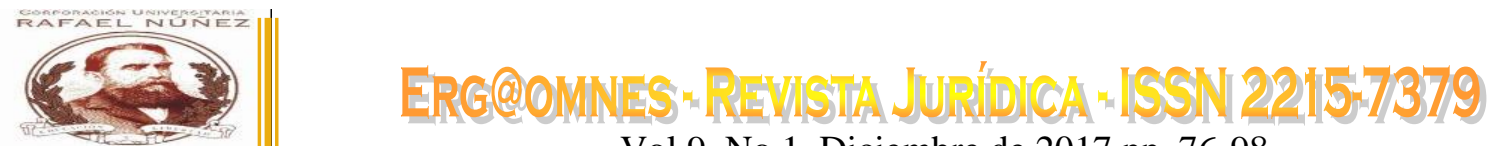

Vol.9, No 1. Diciembre de 2017 pp. 76-98

Artículo Original

Recibido para publicación: Septiembre 20 de 2017.

Aceptado para publicación: Noviembre 17 de 2017

\title{
Justicia y eficacia de la ley 1774 de 2016 en el trato de los humanos con los animales'.
}

\section{Justice and effectiveness of Law 1774 of 2016 on the treatment of humans and animals.}

\author{
Autores: Berrocal Durán Juan Carlos ${ }^{2}$ \\ Reales Vega Rosario Joaquín ${ }^{3}$ \\ Correspondencia: juan.berrocal@curnvirtual.edu.co,rosario.reales@curnvirtual.edu.co
}

\section{RESUMEN}

El presente artículo de investigación pretende demostrar que con la implementación de Albergues para cuidar animales en las ciudades principales del país, se iniciaba en Colombia el acercamiento hacia el buen trato con los animales, denominados por la legislación actual, "seres sintientes". El objetivo general en este artículo hizo referencia a analizar las consideraciones y las interpretaciones que sobre la justicia han hecho pensadores (filósofos, sociólogos y juristas), y la eficacia de la Ley 1774 de 2016 en las relaciones de trato de los humanos con los animales en Colombia. Los objetivos específicos se identificaron por: revisar en el interior del ordenamiento jurídico colombiano los aspectos relacionados con la protección hacia los animales y las consecuencias socio jurídicas que ello ha generado; discernir sobre la eficacia de la Ley 1774 de 2016 con respecto a la relaciones del buen trato hacia los animales en el territorio colombiano. El Método utilizado en esta investigación fue el Inductivo, porque partió de la comprensión del concepto de justicia hacia la eficacia de una norma jurídica como la Ley 1774 de 2016 para el conocimiento de la aplicación de procedimientos de la misma en procura del mejoramiento de las condiciones relacionadas con el trato hacia los animales. Se enmarca en las investigaciones con enfoque analítico - descriptivo y cualitativo, básicamente en las que se inscriben en el ámbito del paradigma Histórico/Hermenéutico. El tipo de investigación definido es de naturaleza cualitativa

\footnotetext{
${ }^{1}$ Este Articulo es resultados del Proyecto de investigación "Consideraciones de Justicia, en las Relaciones de Trato de los Humanos con los Animales", que se encuentra curso, adscrito a la Línea de Investigación Justicia Constitucional, Derecho Penal y Responsabilidad del Estado la cual pertenece al Grupo de Investigación Andrés Bello del Semillero Rafael Wenceslao Núñez Moledo del Programa de Derecho y del Programa de Trabajo Social de la Corporación Universitaria Rafael Núñez. Juan Carlos Berrocal Duran y Rosario Joaquín Reales Vega son los investigadores responsables de este proyecto, y cuenta con la coautoría de Eliana Margarita Moreno Durán, María Teresa Martínez Beltrán, Christian Eduardo Pineda Soto y Freddy Sarmiento Ballesteros, Diana Carolina Castillo Martínez y la egresada Ruth Elena García Terán. Este proyecto nació de la necesidad de saber cómo afecta a la población barranquillera las relaciones de trato de los humanos con los animales. El proyecto ha sido financiado en su totalidad por la Corporación Universitaria Rafael Núñez

${ }^{2}$ Abogado. Especialista en Derecho Laboral. Magíster en Derecho Procesal de la Universidad Simón Bolívar. Doctorante en Ciencias Políticas. Docente/Investigador. Líder del Grupo de Investigación Andrés Bello, del Programa de Derecho de la Corporación Universitaria Rafael Núñez Sede Barranquilla Docente de los Programas de Derecho.

3 Sociólogo. Especialista en Gestión de Proyectos Educativos. Maestreando en Educación de la Universidad Simón Bolívar. Docente/Investigador de los Programa de Trabajo social adscrito al Grupo de Investigación Andrés Bello de la Corporación Universitaria Rafael Núñez Sede Barranquilla.
} 
con la utilización de técnicas y estrategias como el análisis de texto, la entrevista, la encuesta y la observación. Las conclusiones a las que se llegan en el artículo muestran las implicaciones sociales y jurídicas que se generan a partir del maltrato animal por parte de los humanos, ocasionado por el desconocimiento de las circunstancias desventajosas de estos últimos en cuanto a la ética del cuidado, protección y salud de los animales.

Palabras Claves:

Justicia. Eficacia de la ley. Trato de los humanos. Animales sintientes. Dolor animal

\begin{abstract}
With the implementation of shelters to care for animals in the main cities of the country, the approach to good treatment with animals, called by current legislation, "sentient beings" began in Colombia. The general objective of this article was to analyze the considerations and interpretations that thinkers have made about justice (philosophers, sociologists and jurists), and the effectiveness of Law 1774 of 2016 in the treatment of humans with animals In Colombia. The specific objectives were identified by: review within the Colombian legal system aspects related to the protection of animals and the socio-legal consequences that this has generated; discern about the effectiveness of Law 1774 of 2016 regarding the relations of good treatment towards animals in the Colombian territory. The method used in this investigation was the Inductive, because it started from the understanding of the concept of justice towards the effectiveness of a legal standard such as Law 1774 of 2016 for the knowledge of the application of procedures in order to improve the conditions related to the treatment of animals. It is part of the investigations with an analytical - descriptive and qualitative approach, basically in those that fall within the scope of the Historical / Hermeneutical paradigm. The type of research defined is qualitative in nature with the use of techniques and strategies such as text analysis, interview, survey and observation. The conclusions reached in the article show the social and legal implications that are generated from animal abuse by humans, caused by the ignorance of the disadvantageous circumstances of the latter in terms of the ethics of care, protection and animal health.
\end{abstract}

Keywords:

Justice. Efficacy of the law. Treatment of humans. Sentient animals. Animal pain

\title{
Introducción
}

En Colombia, en casi todos los departamentos, las ciudades y los municipios, en las calles y en otros espacios es común encontrar y/o percibir animales abandonados o victimas de mal trato por parte de sus propietarios o de las personas que los utilizan en trabajos pesados o como diversión en espectáculos públicos (circos). Desde la antigüedad se conocen ciertas ideas provenientes de fuentes aceptadas como validas para que los humanos hiciesen uso de los animales para comida, vestido $u$ otras actividades. La primera fuente está relacionada con la costumbre de muchas comunidades de las primeras etapas de 
la vida humana en la Tierra para conseguir comida mediante la caza y la pesca. La segunda fuente proviene del concepto teológico fundamentado desde el "dominio basado en el Génesis" (La Biblia, 2010, p. 5), al momento en que Dios le otorgó a Adán poder para actuar sobre el mundo animal. Por último, el supuesto que se afianza en la no posesión de derechos por parte de los animales por su limitación al no tener capacidad de razonamiento, lenguaje o conciencia.

En la medida que fue evolucionando la sociedad fueron apareciendo disposiciones relacionadas con el trato hacia los animales, por ejempló, en Roma, en los tiempos de Justiniano I, en el "corpus iuris civilis" (Campillo y Restrepo, 2016) ya se encontraba la consideración hacia los intereses de los animales, que mostraba preocupación por su preservación y cuidado en la siguiente forma: El derecho natural es aquello que es dado a cada ser vivo y que no es propio al ser humano.

A partir del Siglo Tres A.E.C. (Antes de la Era Cristiana) las sociedades hindúes y budistas se proclamaron vegetarianas cuando se refirieron al principio de no violencia y por la equivalencia moral entre los seres humanos y los animales. Algunos reyes construyeron hospitales que se encargaban de atender a los animales enfermos. En esta época quien mataba a una vaca era considerado un asesino, similar a un delito como matar un hombre de alta casta; matar a un perro también era considerado como algo serio y castigable. Aunque el Profeta Mahoma (570-632) consideraba que la acción de matar animales, era permisible, esta tenía que estar regulada por una justificación; hacerlo sin necesidad aparente o sevicia, fue tajantemente prohibido.

En todo caso el tema sobre los animales ha sido y es bastante controvertido en la actualidad y existe latente la existencia de no comprensión por parte del humano quien se niega al acatamiento de las disposiciones promulgadas en torno a la defensa de los animales, los cuales necesitan protección y buen trato, pues ello es favorable para la conservación y la armonía del ambiente en el Planeta. Tal 
situación de preocupación se venía planteando desde los postulados de el filósofo John Locke (1632-1704), quien oponiéndose a la posición de Descartes argumentaba que la crueldad con los animales tendrá efectos negativos sobre la evolución ética de los niños, los cuales una vez crecieran transmitirían la brutalidad de sus nociones y gestos sobre la comprensión e interpretación en las relaciones con los seres humanos.

A pesar de haberse realizado muchísimas campañas en pro de la protección animal, Colombia es un país que ha venido a paso lento con respecto a esta relación de buen trato entre humanos y animales, al igual que con la implementación de legislaciones que defiendan y procuren la permanencia de estos últimos. Por eso el creer que los animales no son cosas sino seres que sienten, los hace merecedores de protección. Hay que tener en cuenta que el maltrato animal comprende una variedad de conductas que generan dolor, sufrimiento o estrés a los animales, que van desde la incompetencia para prodigar los cuidados básicos que merecen. En muchas ocasiones se han conocido de casos de asesinato intencional por parte de los humanos hacia los animales.

Año tras año, una gran cantidad de animales llegan a convertirse en víctimas de maltratos por parte tanto de dueños como de personas desconocidas que tienden a ocasionarles lesiones corporales solo por gusto. El abuso hacia los animales es una problemática social de gran escala que no solo afecta a aquellos que son víctimas de esta violencia sino a todos los miembros de la sociedad, al medio ambiente, es decir a la naturaleza.

En esta línea de pensamiento se propone que los animales no son iguales que los humanos y, por lo tanto, no deben ser tratados como tales. Sin embargo, esto de ninguna manera implica que el hombre tiene derecho a maltratar a estos, sino que debe cumplir su función de guardián a fin de que todas las partes de la jerarquía del universo coexistan libres de males. Por lo tanto, aun la teoría más tradicional que sostiene la supremacía del hombre sobre los animales, requiere la provisión de un trato adecuado y humanitario hacia ellos. 
La crueldad que se tiene contra los animales es el tratamiento que genera gran sufrimiento a muchos de ellos. Algunas personas suponen sólo el sufrimiento por simple crueldad hacia los animales; por otro lado se tiene presente el sufrimiento infligido por otras circunstancias, como la producción de carne, la obtención de piel, los experimentos científicos con animales, entre otros. Es de anotar que la crueldad hacia los animales es un asunto de gran relevancia moral, debido a que esta es uno de los componentes de la triada psicopática junto a la piromanía y la enuresis. Un gran porcentaje de los psicópatas reunían estas características en su infancia. Los Derechos de los animales tratan de ayudar a que disminuya el número de animales que son tratados cruelmente.

Centenares de animales padecen cada año mutilaciones, intoxicaciones, electrocuciones y quemaduras en prácticas experimentales; argumentándose que estos sacrificios son en pro del avance de la ciencia, pero a decir verdad la mayoría son generados en la industria bélica, cosmética y en colegios y universidades. Inclusive en los laboratorios de tipo farmacéuticos, los experimentos con animales crean más daños que beneficios. En la actualidad es conocido que muchos medicamentos salieron a la venta después de haber sido experimentados en animales y que han generado enfermedades y malformaciones en las personas.

En las calles del Distrito Especial, Industrial y Portuario de Barranquilla (tomado como referente empírico en este estudio) hay miradas, indiferentes, apáticas, vacías, temerarias y acusadoras, de los humanos hacia los seres sintientes, ya sea abandonados, perdidos o provenientes de las entrañas de la ciudad, pero que tienen un corazón que late, y un sistema metabólico que les permite vivir (de acuerdo con la norma) como sujetos de protección por parte del Estado colombiano y la sociedad que no los tiene que hacer victimas de su antojo o conveniencia, sometidos a sus caprichos.

Las grandes ciudades colombiana que poco a poco se van poblando de estos animales con características de abandono, sin un lugar o sitio que los cobije, o cuando los gobernantes de estas urbes no encuentran una salida más propicia 
Vol.9, No 1. Diciembre de 2017 pp. 76-98

para deshacerse de estos animales abandonados, los sacrifica después de mantenerlos albergados en hacinamiento por poco tiempo, sin misericordia alguna.

Teniendo en cuenta la falta de atención que desde hace muchos años proliferaba en Colombia con respecto al tema del trato hacia los animales, es oportuno realizar el siguiente interrogante en el cual se muestra la relación entre la comprensión de la justicia y la eficacia de la Ley 1774 del 2016: ¿Existe una comprensión de la justicia, y cuáles son las implicaciones de la eficacia de la Ley 1774 de 2016 en las relaciones de trato de los humanos con los animales? Los objetivos específicos se identificaron por: revisar en el interior del ordenamiento jurídico colombiano los aspectos relacionados con la protección hacia los animales y las consecuencias socio jurídicas que ello ha generado; discernir sobre la eficacia de la Ley 1774 de 2016 con respecto a la relaciones del buen trato hacia los animales en el territorio colombiano. El Método utilizado en esta investigación fue el Inductivo, porque partió de la comprensión que se tienen del concepto de justicia y se eleva hacia la eficacia de una norma jurídica como la Ley 1774 de 2016 para el conocimiento de la aplicación de procedimientos de la misma en procura del mejoramiento de las condiciones relacionadas con el trato hacia los animales. Se enmarca en las investigaciones con enfoque analítico descriptivo y cualitativo, básicamente en las que se inscriben en el ámbito del paradigma Histórico/Hermenéutico cuya finalidad es comprender e interpretar. El tipo de investigación definido es de naturaleza cualitativa y por ello se utilizaron técnicas como el análisis de texto, la entrevista, la entrevista, la encuesta y la observación.

Este Articulo forma parte de los resultados parciales del proyecto de investigación "Consideraciones de justicia, en las relaciones de trato de los humanos con los animales", en esta etapa de ejecución, adscrito a la Línea de Investigación Justicia Constitucional, Derecho Penal y Responsabilidad del Estado, desarrollada por el Grupo de Investigación Andrés Bello del Programa de Derecho de la Corporación Universitaria Rafael Núñez Sede Barranquilla, con la 
dirección de Juan Carlos Berrocal Duran y la participación de Rosario Joaquín Reales Vega (en calidad de investigadores asociados), Eliana Margarita Moreno Duran, María Teresa Martínez Beltrán, Freddy Sarmiento Ballesteros y Christian Eduardo Pineda Soto, Diana Carolina Castillo Martínez y la egresada Ruth Elena García Terán miembros del Semillero de Investigación Rafael Wenceslao Núñez Moledo de la Corporación Universitaria Rafael Núñez Sede Barranquilla.

\section{Metodología.}

El método utilizado en esta investigación es el Inductivo, porque parte del la comprensión que se tienen del concepto de justicia y se eleva hacia la eficacia de una norma jurídica como la Ley 1774 de 2016 en la búsqueda del conocimiento sobre la aplicación de procedimientos de la misma en procura del mejoramiento de las condiciones relacionadas con el trato hacia los animales.

Esta investigación se enmarca en los estudios con enfoque analítico descriptivo y cualitativo, básicamente en las que se inscriben en el ámbito del paradigma Histórico/Hermenéutico cuya finalidad es comprender e interpretar. El tipo de investigación definido es de naturaleza cualitativa y por ello se utilizarán técnicas como el análisis de texto, la entrevista, la entrevista y la observación.

El tipo de investigación definido es de naturaleza cualitativa que de acuerdo con Bernal (2010), corresponde a un de tipo de investigación con enfoque cualitativo en el cual se utilizan los siguientes instrumentos o técnicas, de acuerdo con el problema objeto del estudio que se va a realizar y por ello se utilizarán técnicas como el entrevistas, encuestas, análisis de texto y grupos focales entre otras.

El proceso se orientó por la inclusión del enfoque cualitativo, a través de una revisión minuciosa de los postulados sobre justicia, los elementos jurídicos, sociales y la connotación de la Ley 1774 de 2016. En términos generales, la investigación se apoyó en las estrategias adecuadas para la recolección, 
sistematización y análisis de la información obtenida mediante las siguientes técnicas: Recolección y análisis de información relacionada con los planteamientos teóricos de los temas anteriormente referenciados y que fundamentan esta investigación; observación directa de la situación que afectan a algunos animales callejeros y abandonados en la ciudad de Barranquilla; entrevistas con miembros, dirigentes de organización de protección de animales, sociedad civil o de la administración pública (Policía Ambiental).

\section{Resultados y discusión.}

\section{Las interpretaciones y la comprensión sobre justicia en algunos filósofos, sociólogos y juristas.}

A partir de los postulados originados en la Antigua Grecia se dio el inicio de una especie del despertar de la conciencia del hombre, sobre diversas maneras de interpretar la justicia. Con los conceptos sobre la nomos y la Physis, se inició la discusión filosófica sobre las leyes de la naturaleza y las normas que regulan la conducta del hombre. La doctrina de un derecho no escrito, (natural), anterior al hombre se encuentra ya en la literatura griega (Sófocles, p. 4), y su encarnación es Antígona, cuando en Tebas, frente al Palacio de los Reyes, increpa valerosa a Creonte, por haber expedido la norma con la que se ordenaba que el cadáver de su hermano, fuese abandonado sin sepultar y sin ninguna clase de ofrenda. El dialogo en la obra trágica de Sófocles (Antígona) es el siguiente:

Zeus - dice Antígona- no promulgó esas leyes (las de Creón). Tampoco la justicia que tiene su trono entre los dioses del averno. No, ellos no han impuesto tales leyes a los hombres. No podía penar que las normas fueran de tal calidad que yo por ellas dejara de cumplir otras leyes aunque no escritas, fijas siempre, inmutables, divinas. No 
son leyes de hoy, no son leyes de ayer... son leyes eternas y nadie sabe cuándo comenzaron su vigencia. ¿lba yo a pisotear esas leyes venerables, impuestas por los dioses, ante la antojadiza voluntad de un nombre, fuera quien fuera?" (p. 4).

La concepción que el hombre tenía en el pasado, consistía en cazar animales y sacrificarlos y esto se justificaba para la sobrevivencia alimentaria del mismo hombre. Con el paso del tiempo y la misma necesidad evolutiva, el hombre de la antigüedad fue encaminando la caza hacia otros caminos distintos al de la sobrevivencia y la convirtió en una especie de deporte que se fue tornando un vicio inescrupuloso, que posteriormente lo conduciría a cometer actos barbaros de matanza y maltrato en contra de las especies de animales, porque los consideraba un peligro a los que debía exterminar.

En la Edad de Piedra los antepasados del hombre fundamentaban la alimentación en la recolección y almacenamiento de plantas y frutas silvestres. Sin embargo, esta situación tubo una variante originada por el descubrimiento de fuego, la gran revolución que le permitió la fabricación de armas y una visión e interpretación del mundo desde otra perspectiva. Una alternativa de caza al principio de la Edad de Piedra consistió en ahuyentar a los animales, con el uso de antorchas y fogatas, conduciéndolos hacia precipicios o barrancos en los que caían. Con esta técnica cazaban bisontes, leones, caballos, osos, ciervos, jabalíes, etcétera. Utilizaban también armas hechas con piedra, huesos, como mazas, cerbatanas, etcétera, con las que producían dolor o adormecimiento. Esta situación les proporcionaba usar su carne, piel o también para competir y mostrarse como en más fuerte.

Al parecer, tanto en el periodo Neandertal como en los que le siguieron, el hombre primitivo comía la carne de los animales que tenía a su alcance o estaban disponibles en un determinado lugar o en una determinada época. El hombre del 
Neandertal tenía la facultad de combinar las actividades relacionadas con la caza de animales con las de rapiña de algunos animales muertos. Para el hombre primitivo, la degustación de carnes se convirtió en algo vital, al igual que la vestidura con las pieles de los animales que cazaba, ya que los cambios en el clima se presentaban en forma imprevista, por lo que se veía obligado a cambiar de lugar donde habitaba cada vez que la ocasión lo requería.

La historia de la humanidad precisa que hace probablemente unos 90.000 a 80.000 años, el ser humano en Katanga (actualmente República Democrática del Congo) pescaba grandes cantidades de peces y moluscos, utilizando puntas de huesos. Esta forma de interactuar con los seres de la naturaleza, se puede tomar como un ejemplo (tal vez el más rudimentario) de la intención del hombre por preservar a los animales.

Es de anotar que cuando se hace referencia a la crueldad hacia los animales, considerada por Medina Chávez (2009) quien desde una óptica con perspectiva social lo percibe como:

el tratamiento que causa sufrimiento o daño a estos. La definición de sufrimiento inaceptable varía. Algunos consideran sólo el sufrimiento por simple crueldad a los animales, mientras que otros incluyen el sufrimiento infligido por otras razones, como la producción de carne, la obtención de piel, los experimentos científicos con animales y las industrias de huevos. Muchas personas consideran la crueldad hacia los animales como un asunto de gran importancia moral. La crueldad animal es uno de los componentes de la triada psicopática junto a la piromanía y la neurosis. Un gran porcentaje de los psicópatas reunían estas características en su infancia.

El autor de la referencia anterior plantea que los derechos de los animales buscan la forma de ayudar a la disminución del número hasta ahora creciente de 
estos los cuales son tratados en forma cruel y establece cifras anuales que pasan de millones de animales que son mutilados, intoxicados, electrocutados y quemados en experimentos, con los exabruptos de argumentos que justifican tales sacrificios en nombre de la ciencia, con los cuales se causan sufrimiento, pero al mismo tiempo causan enfermedades y malformaciones en los seres humanos. Estos aspectos denotan que aunque existan diferencias también existe una identidad y esta es la capacidad de sufrir, que es común tanto a humanos como a animales.

La comisión de actos de crueldad contra los animales está fuertemente influenciada por la cultura o pseudo-culturas en las que se manifiesta. Pero esto, lejos de ser impedimento en la investigación de sus orígenes, causas y consecuencias, es una oportunidad de desentrañar las muchas influencias que pueden incidir en la formación de un comportamiento violento.

En la sociedad actual se requiere mostrar por qué el uso de los animales para propósitos de experimentos humanos es incorrecto, ya que se usan animales tanto como en investigaciones médicas como para científicas, en las pruebas médicas los resultados que se obtienen en animales no son definitivas ya que tienen que ser investigadas más a fondo, puesto que el funcionamiento del organismo no es el mismo en los animales usados en los laboratorios a el de otros animales y en las investigaciones científicas muchas veces se usan para realizar estudios sin sentido, hechos sólo por curiosidad.

La experimentación en animales es una práctica que ha sido aceptada por muchos años, se calcula que al un aproximado de 15 millones de animales son usados en investigaciones cada año, desde que ha empezado la evolución hasta tiempos recientes, empleando como argumentos que los animales son seres creados por Dios para el uso humano, seres que no poseen alma y por lo tanto, tampoco sentimientos, que no podían sentir dolor alguno y que los gemidos o ruidos que producían el ser maltratados no tenían significado alguno, ya que como no sentían dolor entonces era imposible que se quejaran. La investigación se 
fundamenta en la teoría de los derechos y para ello se hace referencia a lo que los autores han planteado frente a salvaguardar los intereses que tanto las personas 0 los animales tienen. Esta teoría coloca el énfasis en los derechos que protegen los intereses que las personas tienen, sin ninguna clase de interferencia y con el acceso a ciertos bienes que no pueden ser dañados por otras personas en su beneficio o en beneficio de otras

Esta teoría alude a definir cuáles son los diferentes derechos que posen las personas y los animales, desde el punto de vista moral o a los derechos legales, los cuales se presentan en la siguiente forma: Los derechos legales son concebidos como aquellos con los cuales nace todo individuos, y que se obtienen con independencia de si se poseen o no derechos legales que los protejan. Sin embargo, algunos teóricos no creen en la existencia de derechos morales, pero a diferencia, defienden los derechos legales para los animales no humanos como la forma con la cual ellos protegen sus propios intereses.

En la actualidad, existen diferentes teorías sobre los derechos morales, y cada una presenta su propio punto de visita de acuerdo a las interpretaciones y exposiciones que han realizado, como es el caso actual en el asegura Oscar Horta (2009: 37), haciendo alusión a los planteamientos encontrados en la página de Ética Animal donde citan a Christine Korsgaard (2005) y Julián Franklin (2005) "quienes asumen y defienden la posición de Inmanuel Kant, por un lado, pero no comparten su conclusión en el sentido de los derechos los cuales deberían aplicarse de manera exclusiva a los seres humanos".

Estos investigadores se han pronunciado frente al tema, que los animales no humanos son sintientes, y si se estuviera en su lugar no podría considerarse aceptable que los intereses de cada persona fuesen pasados por alto. Por lo tanto, no solamente los seres humanos deberían ser considerados como fines en sí, sino todos los animales sintientes.

En la misma de la referencia anterior, se cita lo expuesto por Tom Regan (2004) quien defiende los derechos morales de los animales no humanos. 
Él considera que se tiene la obligación moral a rechazar cualquier teoría que niegue los deberes directos hacia los animales, o que afirme que solamente los humanos tienen valor inherente. Regan usa el criterio de "sujeto de una vida. Según él, cualquiera que sea "sujeto de una vida" tiene valor inherente. Esto incluye no solamente a los humanos, sino a los animales".

Al igual que lo plantea en Ética Animal, Gary Francione (2000) es otro de los teóricos que ha defiende los derechos de los animales y en él se encuentra plasmado el alegato que consiste en que los animales poseen derechos legales y derechos morales que según él son el derecho básico de no ser usados como recursos por otros y porque son seres sintientes.

Uno de los pensadores que mejor define el concepto de justicia animal es el filósofo Jeremy Bentham quien es retomado por el blog o bitácora Vida Animal En Peligro (2017), quien postulo:

los animales por su capacidad de sentir agonía y sufrimiento, independientemente de que tuviesen la capacidad de diferenciar entre "bien" y "mal" (una capacidad que algunos discapacitados psíquicos no tienen) deben tener unos derechos fundamentales como el derecho a la vida y a su seguridad, y a estar libres de la tortura y de la esclavitud. Él también dedujo que un perro es más aprehensivo que un recién nacido y que de este modo estaría más cercano al humano adulto que un bebé. Con sus tesis y comparaciones que hacen referencia a los miembros de la propia especie, "los cuales carecen de calidad de personas normales, parece imposible que su vida fuera más válida que la de unos animales (s.p)

\section{Las interpretaciones de justicia respecto a los seres sintientes}

Al interpretar la Corte Constitucional el sentir de los animales y prohibir los tratos crueles hacia estos seres sintientes en la Sentencia C-666 de 2010 esta 
presenta una serie de contradicciones, ya que la Corte Constitucional al realizar el control de constitucionalidad de la Ley 84 de 1989 en su artículo 7, la declara exequible, pero permite, el rejoneo, coleo, corridas de toros, corralejas, peleas de de gallos. La Corte Constitucional (Sentencia C 666 de 2010) plantea que estos deben "recibir protección especial contra el sufrimiento y el dolor durante el transcurso de esas actividades". (p.79), lo que sería mucho más amable para el hombre común si los jueces entendieran que cuando se maltrata a un animal el que sufre la indignación es el propio hombre que le indigna que otro hombre maltrate a un animal

El Código Civil Colombiano en el artículo 655 se refiere a los animales como cosas al expresa lo siguiente" Muebles son las que pueden transportarse de un lugar a otro, sea moviéndose ellas a sí mismas como los animales (que por eso se llaman semovientes), sea que sólo se muevan por una fuerza externa, como las cosas inanimadas" artículo que fue modificado por la Ley 1774 de 2016, en el artículo 1 de manera clara dice que los animales son seres sintientes y no son cosas pero en el artículo 2 de la misma ley reproduce íntegramente el artículo 655, entrando el legislador en una contradicción al plantear nuevamente que los animales son cosas.

Se entiende atraves de la legislación y las interpretaciones de la Corte Constitucional que los animales son seres sintientes que se deben proteger; esta contradicción debió de ser aclarada por la propia Corte Constitucional ya que le correspondía expedir una sentencia interpretativa con el fin de que se lograra entender cómo deberíamos interpretar el precepto legal o declarar el articulo 2 como inexequible y no convertirse la Corte Constitucional en un ciego de pensamiento al expresar que las contradicciones de las normas jurídicas en el lenguaje que emplea el legislador "sólo puede ser objeto de control constitucional cuando afecta a los seres humanos. En este caso se afecta a los animales, así que no es procedente". (p.4). Así lo manifestó en su Salvamentos y aclaración de voto la Magistrada María Victoria Calle Correa, en la Sentencia C-467 de 2016 
Lo que da a entender que para la Corte Constitucional lo que afecte a los animales no es importante y por lo tanto no es de rango constitucional. Se olvida la Corte que cuando se maltrata a un animal, el ser humano se siente ofendido e indignado Así se expresa la magistrada María Victoria Calle Correa, en la Sentencia C-467 de 2016 al conceptuar: "El Congreso de la República, con errores y contradicciones, avanza progresivamente en procura de un trato digno hacia los animales, este Tribunal sigue defendiendo una concepción de los animales basada en el derecho civil, pero incompatible con la Carta Política"

Los autores creen que se debe tener en cuenta, por parte de la Corte Constitucional y por parte del Legislador el artículo 13 de la Constitución Nacional cuando esta hace alusión a la igualdad material, en razón que se debe asumir un trato digno con los animales es decir tratar a estos como desiguales o diferentes frente al hombre, pero que son seres que merecen especial protección por parte del Estado como lo expresa Berrocal Duran en un artículo publicado en la revista justicia (2016)

La igualdad es un criterio puramente formal: consiste en tratar de igual manera a los iguales y de manera desigual a los desiguales. Su carácter formal radica en que se limita a establecer un criterio general de actuación con respecto a los iguales y a los desiguales Además, no se es igual o desigual en abstracto, sino siempre en relación con un elemento de comparación. Una vez que se hayan establecido las clasificaciones pertinentes de los individuos en virtud de la igualdad y desigualdad respecto a determinados factores de comparación se podrá proceder a tratar igualmente a los iguales y desigualmente a los desiguales (p.24)

El acercamiento realizado para conocer de la Sociedad de Barranquilla los aspectos relacionados con el maltrato hacia los animales se produjo con las 
personas que en calidad de administradores o gerentes de clínicas veterinarias y organizaciones protectoras de animales o funcionarios de la policía Ambiental conocen sobre la normativa colombiana vigente sobre el trato hacia los animales.

En primera instancia con un grupo focal conformado por diez personas los investigadores se dedicaron a explorar los conocimientos de las personas seleccionadas como informantes calificados para conocer lo que ellos, desde su comprensión tenían inculcado sobre la norma y la forma como habían interpretado su aplicación y eficacia en la práctica, Los aspectos de la comprensión, interpretación y eficacia giraron en torno a tres preguntan con las cuales se desarrolló el diálogo.

Las respuestas del grupo focal fueron consignadas en la Matriz, que a continuación se presenta en las siguientes líneas, no sin antes dirimir algunas disensiones y posteriormente puesta en consenso.

Matriz de Diálogo 1. Las interpretaciones y la eficacia de la Norma

\begin{tabular}{|c|c|c|}
\hline Integrantes del Grupo & $\begin{array}{l}\text { Conocimiento de la } \\
\text { Norma }\end{array}$ & $\begin{array}{l}\text { Aplicación y eficacia de la } \\
\text { Norma }\end{array}$ \\
\hline Policía Ambiental & Si la Conocen & $\begin{array}{l}\text { Hasta ahora se está } \\
\text { haciendo y cumpliendo } \\
\text { con las denuncias y el } \\
\text { conocimiento de los } \\
\text { casos que sobre maltrato } \\
\text { se presentan. }\end{array}$ \\
\hline $\begin{array}{l}\text { Directores } \\
\text { Organizaciones }\end{array}$ & $\begin{array}{l}\text { Si la Conocen y están } \\
\text { deseosos de } \\
\text { aplicación }\end{array}$ & $\begin{array}{l}\text { Se siguen presentando } \\
\text { abusos hacia los } \\
\text { animales que desmienten } \\
\text { que se esté aplicando la } \\
\text { norma en forma cabal y } \\
\text { correcta. }\end{array}$ \\
\hline Gerentes de Veterinarias & $\begin{array}{l}\text { Si la Conocen y procuran } \\
\text { por su aplicación }\end{array}$ & $\begin{array}{l}\text { Todavía se observan } \\
\text { casos de abuso contra los } \\
\text { animales }\end{array}$ \\
\hline
\end{tabular}

Fuente: Grupo Focal organizado en Barranquilla, mayo de 2017.

\section{Abandono y maltrato de animales}


En términos universales el maltrato animal es definido por telesur (2016) ${ }^{4}$ "como un comportamiento irracional de una persona hacia un animal con el objetivo de causarle sufrimiento, estrés o, incluso, puede llevarlo a la muerte". Este maltrato animal se evidencia a partir del abandono de ellos hasta ilógicamente por lo, permitido por la corte constitucional como son los eventos y espectáculos públicos como son el rejoneo, coleo, corridas de toros, corralejas, peleas de de gallos. $\mathrm{Y}$ algunas actividades ilícitas que como la compraventa de animales exóticos, la comercialización de pieles son las maneras a las que un animal es sometido al maltrato.

El abandono animal es otra de las grandes dificultades que afectan a la sociedad colombiana y al mundo. En efecto con la promulgación del a Ley 1774 de 2016 obliga a la población a no abandonar a los animales, es decir a no ser expulsados por sus dueños a la calle y que estos padezcan hambre, estén sucios, con enfermedades que pongan su vida en peligro y la de los seres humanos. Lo que obliga la norma jurídica a la sociedad y a las autoridades es a proteger a los animales ya que el artículo 3 es claro y contundente al expresarse de la siguiente manera:

Protección animal El trato a los animales se basa en el respeto, la solidaridad, la compasión, la ética, la justicia, el cuidado, la prevención del sufrimiento, la erradicación del cautiverio y el abandono, así como de cualquier forma de abuso, maltrato, violencia, y trato cruel (2016, p.1).

El ser humano en cuanto a la superioridad que cree sentir sobre la naturaleza por su soberbia hace extensiva el dominio hacia los animales, abusando de su poder o sobre ellos maltratándolos o expulsándolos de sus hogares.

Afortunadamente existen personas que abanderan la protección de los animales, se fundamentan en la dignidad humana y el respeto hacia la vida de los

\footnotetext{
${ }^{4}$ https://www.telesurtv.net/telesuragenda/El-maltrato-animal-20160726-0035.html
} 
seres humanos como de los animales. Este respeto hacia los animales les garantiza el derecho a existir en condiciones dignas y justas tomando la defensa de los seres sintientes y hablando por ellos. Se busca que el estado garantice sus derechos y los incluya dentro de la protección animal. Tal es el caso de lo planteado por Peter Singer en su texto Liberación Animal (1990)

Tenemos que alzar la voz por los que no pueden hablar por sí mismos. Podemos darnos cuenta de la importancia de este obstáculo preguntándonos cuánto habrían tenido que esperar los negros por la igualdad de derechos de no haber podido levantarse en grupo y exigirla. (p.20)

En esta instancia se presenta la sistematización de una encuesta con enfoque cualitativa aplicada a una muestra intencional conformada por 50 individuos de varios estratos de la ciudad de Barranquilla. Los resultados de esta actividad aparecen consignados en las siguientes Tablas de datos.

Tabla 1. Expresiones de la sociedad civil frente al maltrato de animales en Barranquilla

\begin{tabular}{|l|c|l|l|l|l|l|l|l|l|l|}
\hline \multicolumn{4}{|l|}{ Maltrato animal } & \multicolumn{3}{|l|}{ Los animales sienten } & \multicolumn{3}{|l|}{$\begin{array}{l}\text { Padecimiento del } \\
\text { animal }\end{array}$} & \multicolumn{2}{l|}{$\begin{array}{l}\text { Abandono en la } \\
\text { calle }\end{array}$} \\
\hline $\begin{array}{l}\text { En } \\
\text { contra }\end{array}$ & A favor & Si & No & Tal vez & Si & No & Tal vez & Si & No & Tal vez \\
\hline 100 & 0 & 100 & 0 & 0 & 10 & 80 & 0 & 0 & 100 & 0 \\
\hline
\end{tabular}

Fuente: Encuesta aplicada a población civil en Barranquilla, mayo 2017

Las respuestas a este primer aspecto relacionado con la información que tiene la sociedad civil en cuanto al maltrato animal evidencia que en su gran mayoría existe consenso a la forma como se percibe el deber de proteger a los animales. Un $10 \%$ de las personas encuestadas encontró que es permisible dejar pasar a los animales padecimiento y no existió una justificación clara sobre el particular

Tabla 2. Expresiones de la sociedad civil frente al maltrato de animales en Barranquilla 
Vol.9, No 1. Diciembre de 2017 pp. 76-98

\begin{tabular}{|c|c|c|c|c|c|c|c|c|c|c|}
\hline \multicolumn{3}{|c|}{$\begin{array}{ll}\text { Grado } & \text { de } \\
\text { abandono } & \end{array}$} & \multicolumn{3}{|c|}{$\begin{array}{l}\text { Cuidado de } \\
\text { los animales }\end{array}$} & \multicolumn{5}{|c|}{ Maltrato de los animales } \\
\hline $\mathrm{Si}$ & No & $\begin{array}{l}\text { Tal } \\
\text { vez }\end{array}$ & Irr & $\mathrm{HB}$ & $\mathrm{CC}$ & Enoj & Crueldad & Venganza & Beneficio & Descono \\
\hline 70 & 10 & 20 & 75 & 5 & 20 & 5 & 80 & 0 & 0 & 15 \\
\hline
\end{tabular}

Fuente: Encuesta aplicada a población civil en Barranquilla, mayo 2017.

De estos tres indicadores (grado de abandono de los animales, cuidado de los animales y maltrato de los animales) se presentan diferencias significativas entre las repuestas aportadas por la sociedad civil; mientras el $70 \%$ dice percibir cierto grado de abandono en los animales, sobre todo cuando ha observado que no tienen dolientes ni a alguien que se preocupe por este estado, el $20 \%$ manifiesta que tal vez no percibe malestar ni grado de abandono en los animales o porque no ha preguntado sobre la propiedad de los mismos. Un $10 \%$ cree que los animales no se encuentran en estado de abandono aunque no saben sobre la pertenencia del animal.

En lo que hace referencia al cuidado de los animales los habitantes de la ciudad de Barranquilla al examinar el nivel de cuidado que estos merecen por parte de los propietarios, la respuesta en $75 \%$ que esto se debe por irresponsabilidad de los humanos que tiene a cargo mascotas, a sabiendas que está obligados a prodigarles atención y cuidado. El 20\% de los encuestados dice que esto los obligará a adquirir conciencia sobre el compromiso por el cuidado y el $5 \%$ establece que cuando el dueño del animal o los animales procede en forma descuidada hacia este ser, le está ayudando a proporcionarle bienestar.

Por último, en cuanto a lo que se piensa sobre el por qué se maltrata a los animales, un $80 \%$ de los entrevistados dijo que esto se debe a una excesiva crueldad por parte del humano, mientras que el 15\% le achacó el maltrato al desconocimiento de la norma. Como quiera que estas son las percepciones de la ciudadanía tiene sobre el maltrato animal sería conveniente en otra etapa de la investigación cruzar esta información con otras técnicas que permitan adentrarse en cada uno de los significados que estas personas le dieron a sus respuestas. 
Cabe resaltar que es un avance considerable el hecho de reconocer que los animales ya no sean considerados cosas dentro del Código Civil en el artículo 655 a pesar de la contradicción del legislador y tener en cuenta que ya estos abusos no deben quedar en la impunidad a través de multas económicas que van desde 5 a 50 salarios mínimos mensuales legales vigentes y penas que van de 12 a 36 meses de cárcel. Esta es la norma que desarrolla en mayor profundidad la idea de la protección animal.

Esta ley proporciona a la Policía Nacional facultades que antes no tenía: la aprehensión preventiva de los animales sobre los cuales hay graves indicios de maltrato, pues hoy no hay ninguna herramienta jurídica para que el Estado lo recupere y lo proteja. Como seres sintientes, los animales se convierten en sujetos de protección por parte del Estado y de las autoridades.

\section{Conclusiones.}

Las consideraciones éticas que se derivan de este estudio son fundamentales y en cierto momento, constituyen la responsabilidad ante la información que suministraran los directivos de las organizaciones ambientalistas, los administradores y o gerentes de las clínicas veterinarias de la cuidad de la ciudad de Barranquilla, los funcionarios públicos de la Policía Ambiental y las personas de la sociedad civil. La confiabilidad ante los datos que se suministran es el pretexto y garante de la investigación. Durante el proceso y al final de la misma en la que se muestra la visibilización de las incidencias que, desde lo social, jurídico, político y ambiental se presenta en un marco permeado por la diversidad de cultura e intereses.

Si se tienen en cuenta las implicaciones jurídicas que se generan a partir del maltrato animal ocasionados por las circunstancias desventajosas de estos, es importante que se tenga el conocimiento por parte de los estudiosos del Derecho el cuidado y salud de los animales, en esta dinámica se presentan los resultados de esta investigación que en términos generales se orienta por determinar cómo 
la justicia y la sociedad garantizan la vida, el buen trato a los animales afectados con el fin de luchar en hacer valer los derechos de estos como seres vivos.

En la Liberación animal, el famoso libro de Peter Singer - y el predilecto de las organizaciones protectoras de animales de todo el mundo- este proporcionó una frase que ha servido como epígrafe al título que estable, "todos los animales son iguales...o por el principio ético que fundamenta la igualdad entre los humanos exige que también extendamos la igualdad a los animales" (1990: p.37), y dejó la concepción que serviría posteriormente para que el concepto que se tenía de los animales como cosas, o como no humanos, pasase al de seres sintientes, es decir, como los demás animales que se encuentran en la Tierra, entre ellos los humanos, a los cuales les asiste derecho.

En la Legislación Colombiana, sobre todo en la actual Ley 1774 de 2016 (2016) mejor conocida como la ley contra el maltrato animal y en las otras disposiciones que le precedieron se han notado avances en cuanto al trato que deben recibir los animales por parte de los humanos, se ha mejorado ostensiblemente y la sociedad ya es consciente de que estos son seres sientes y que tienen derechos.

Pese a lo que se considera un gran avance en materia jurídica y social al principio, por cuanto es un gran precedente para lo que en un futuro podría ser el reconocimiento de una subjetividad jurídica animal dentro de la legislación colombiana, al proclamar que los animales son seres sintiente, es necesario e imperioso resaltar que dicha ley podría convertirse en un gran hito para lo que podría ser el abandono de la visión antropocentrista sobre la cual versa el Derecho,

En esta forma, se puede evidenciar que la Ley 1774 puede llegar a resultar un arma de "doble filo", pues así como muchos celebran su promulgación, otros han visionado con desconfianza a la misma, principalmente por la contradicción del propio legislador al decir que los animales no son cosas y después decir que si 
lo son. Sin olvidar las contradicciones de la misma Corte Constitucional. Aún falta mucho camino por recorrer.

\section{Referencias.}

Bernal, C.A. (2010), Metodología de la investigación. Tercera edición. Bogotá. Pearson

Berrocal Duran J.C. (2016). Igualdad material de las partes en el proceso laboral: audiencias, conciliación y primera de trámite. En: Revista Justicia, 30 (Diciembre 2016) p 122-131. Disponible en:

file:///D:/Berrocal/Mis\%20documentos/Downloads/760-749-1-PB\%20(9).pdf

Biblia. Reina Valera Gomez (2010). Génesis. Recuperado en: https://www.bibliatodo.com/la-biblia/Reina-valera-Gomez/genesis-1

Campillo Pardo, A. J; Restrepo Z, J. (2016) El Corpus luris Civilis: la recopilación más importante del derecho romano. Colegio Mayor de Nuestra Señora del Rosario. Recuperado en:

http://www.urosario.edu.co/Blog-Archivo-Historico/Lenguas-clasicas/Abril2016/El-Corpus-Iuris-Civilis-La-recopilacion-mas-import/

Colombia. Congreso de la Republica. (2016). Ley 1774 de 2016 Publicado en Diario Oficial 49747 de enero 06 de 2016. Disponible en: http://www.alcaldiabogota.gov.co/sisjur/normas/Norma1.jsp?i=64468

Colombia. Congreso de la Republica. (1989). Ley 84 de 1989. Publicado en Diario Oficial 39120 de diciembre 27 de 1989. Disponible en: http://www.alcaldiabogota.gov.co/sisjur/normas/Norma1.jsp?i=8242 
Colombia. Congreso de la Republica. (1887).Ley 57 de 1887 Nivel Nacional (Código Civil) Disponible en:

http://www.alcaldiabogota.gov.co/sisjur/normas/Norma1.jsp?i=39535

Colombia, Corte Constitucional. (2016) Sentencia C-467 de 2016 recuperada en: http://www.alcaldiabogota.gov.co/sisjur/normas/Norma1.jsp?i=66881

Colombia, Corte Constitucional. (2010) sentencia c- 666 de 2010 recuperada en: http://www.corteconstitucional.gov.co/relatoria/2010/C-666-10.htm

Correa, M., Jaimes, J., Cardozo, S. \& Mantilla, C. (2013). Estrategia para la disminución de violencias en la escuela en la ciudad de Bucaramanga. Revista Justicia, 18(24), 14-24. Recuperado de http://publicaciones.unisimonbolivar.edu.co/rdigital/ojs/index.php/justicia/article/v iewFile/136/138

Ética Animal. (2017). Teorías de los derechos: diferentes posiciones. Diciembre 1, de Ética Animal Sitio web: http://www.animal-ethics.org/etica-animalesseccion/teorias-eticas-animales-no-humanos/teorias-derechos-diferentesposiciones/\#fn2

Horta, O. (2009). Ética Animal. El cuestionamiento del antropocentrismo: distintos enfoques normativos. En: Revista Bioética y derecho, No. 16 (abril 2009); p. 36-39. Disponible en: http://www.bioeticayderecho.ub.es

Medina Chávez, G. (2009) Maltrato Animal Recuperado en: http://theworldismin3.blogspot.com.co/

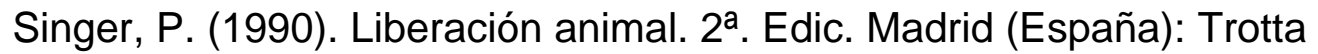


Sófocles. (2001). Antígona. Pehuén editor. Recuperado en: http://www.pehuen.cl/files/pdf/ANTIGONA.PDF

Trejos, L. (2013). Aproximación a las dinámicas del crimen organizado en la ciudad de Barranquilla. El caso del Frente José Pablo Díaz de las Autodefensas Unidas de Colombia (200-2006). Justicia, 118-134.

Vida Animal En Peligro. (2017). Importancia De La Vida Animal. Diciembre 1, de Vida Animal En Peligro Sitio web: https://juanquevedo.wordpress.com/

Vega, H. (2015). Aspectos dogmáticos y políticos criminales de la estructura general del delito en el sistema penal colombiano. Justicia, 27, 42-72. Recuperado de http://dx.doi.org/10.17081/just.3.27.320

Yáñez, M. (2013). El desplazamiento forzado en la jurisprudencia de la Corte Constitucional colombiana (1991-2003): momento previo a la declaratoria forma del estado de cosas inconstitucional. Revista Justicia, (23), 191-218. Barranquilla: Universidad Simón Bolívar 